\title{
Lepromatous Leprosy and Human Immunodeficiency Virus: A Rare Co-infection
}

\author{
Marie Len A. Camaclang ${ }^{1}$ and Eileen Liesl A. Cubillan ${ }^{2}$ \\ ${ }^{1}$ Section of Dermatology, Department of Medicine, Philippine General Hospital, University of the Philippines Manila \\ ${ }^{2}$ Section of Dermatology, Department of Medicine, College of Medicine and Philippine General Hospital, University of the Philippines Manila
}

\begin{abstract}
We report a 23-year-old male with lepromatous leprosy atypically presenting with 5-year history of asymptomatic, verrucous papules, and nodules. Human Immunodeficiency Virus (HIV) testing was positive with depressed CD4 count. In HIV/leprosy co-infection, most of the documented patients were diagnosed with paucibacillary leprosy as immune reconstitution disease (IRD) from treatment-induced immunological recovery. Rarely, multibacillary lepromatous leprosy is encountered in the setting of untreated, severe immunodeficiency. Atypical clinical presentation warrants investigation for concurrent HIV infection.
\end{abstract}

Key Words: leprosy, lepromatous leprosy, human immunodeficiency virus, coinfection, verrucous

\section{INTRODUCTION}

Leprosy has a variety of clinical and histopathological presentations, which heavily rely on the interaction between Mycobacterium leprae antigens and their recognition by the individual's cell-mediated immunity (CMI). The spectrum of leprosy, based on the Ridley-Jopling classification, describes tuberculoid leprosy on one pole, and lepromatous leprosy on the other, with the latter having high bacilli load consequential of poor or absent CMI response. ${ }^{1}$

The rise in the incidence of human immunodeficiency virus (HIV) infection in recent years, with the concomitant increase in the incidence of tuberculosis, another mycobacterial disease, has raised concern regarding the possibility of a similar pattern in leprosy. However, studies

Paper presented at the Philippine Society of Venereologists Inc. (PSVI) Biennial Convention, October 3-5, 2018, $1^{\text {st }}$ place, PSVI National STI Case Report Contest, Quezon City, Philippines.

E-poster presented at the $27^{\text {th }}$ European Academy of Dermatology and Venereology Congress, September 12-16, 2018, Paris, France.

E-poster presented at the $40^{\text {th }}$ Annual Convention of the Philippine Dermatological Society, November 8-10, 2017, EDSA Shangri-La, Mandaluyong City, Philippines.

Poster presented at the 2019 American Academy of Dermatology Annual Meeting, March 1-5, 2019, Washington DC, USA.

Corresponding author: Marie Len A. Camaclang, MD

Section of Dermatology

Department of Medicine

Philippine General Hospital

University of the Philippines Manila

Taft Avenue, Manila 1000, Philippines

Telephone: +632 5548400 local 5105/5106

Email: macamaclang@up.edu.ph have shown that the host granulomatous response in leprosy, in contrast to tuberculosis, is not altered by HIV co-infection; each progresses as a separate infection independent of each other. ${ }^{2,3}$ Interestingly, despite both lepromatous leprosy and HIV infection being characterized by depressed CMI, this co-infection is rarely encountered.

We report an unusual case of lepromatous leprosy presenting with verrucous lesions, in the setting of untreated, severe immunodeficiency.

\section{CASE REPORT}

A 23-year old male presented with a five-year history of asymptomatic, hyperkeratotic papules and nodules, initially presenting on bilateral dorsal feet, with gradual spread to the extremities, trunk and hands. There were no reported symptoms of pain, pruritus, paresthesia, or numbness. The papules were noted to enlarge and increase in number, 
forming verrucous plaques, associated with scaling and crusting. Persistence and progression of lesions, particularly nasal disfigurement, prompted consult at the outpatient department. Review of systems and past medical history were unremarkable.

The patient has a family history of pulmonary tuberculosis but denied infection. He is the youngest of nine children, with no known vices. He completed secondary schooling, and used to do clerk work at a computer shop. He denied previous and/or current sexual relationship/s.

On physical examination, there were multiple welldefined, round to irregularly-shaped, flesh-colored to erythematous, verrucous papules and plaques, some with noted crusting and ulceration on the acral areas (Figure 1A). Multiple well-defined erythematous to pale-pink plaques and nodules were prominent on the central face and ears, and pink-colored, well-defined nodular to polypoidal protrusions from the nasal tip and alae, with conspicuous alar rim and nasal tip deformities; there was loss of bilateral lateral eyebrows (Figure 1B and 1C). There were also multiple well-defined erythematous to flesh-colored verrucous papules, nodules, plaques on the trunk and upper extremities, and multiple irregularly-shaped, well-defined hyperpigmented patches and plaques, and xerosis of the distal lower extremities. On nerve assessment, there was enlargement and tenderness on palpation of the left ulnar nerve. On sensory assessment, there was loss of protective sensation on bilateral palms and soles. The rest of the nerve assessment was normal (Figure 2).

Punch biopsies of selected lesions from the acral areas and the nose showed diffuse granulomatous dermatitis, and acid-fast bacilli on Fite Faraco stain (Figure 3). Slit skin smear showed numerous solid bacilli in globi from all specimen sites.

No known risk factors for an immunodeficient status were elicited from history and clinical examination. However, the patient's atypical clinical presentation prompted HIV testing. HIV screening and confirmatory tests were positive, with viral load of 9, 372, $551.78 \mathrm{IU} / \mathrm{mL}$ and CD4 count of 106 cells/uL. Chest radiograph findings were normal. On hepatitis profile, the patient was reactive to Hepatitis $\mathrm{C}$ virus ( $\mathrm{HCV}$ ), which may indicate past hepatitis $\mathrm{C}$ infection. On complete blood count, the patient had mild anemia with other blood parameters being normal. Cardiac, pulmonary, hepatic, and renal evaluation, as well as the rest of the metabolic parameters were normal. Patient has been referred to the Sexually transmitted disease/Acquired immunodeficiency syndrome (STD/AIDS) Guidance Intervention Prevention (SAGIP) clinic.

The patient was started on multidrug therapy (MDT) for leprosy, with noted improvement of cutaneous lesions. He was also referred to Ophthalmology, Otorhinolaryngology (ORL), and Rehabilitation Medicine for co-management. He was, however, lost to follow up. He has been found
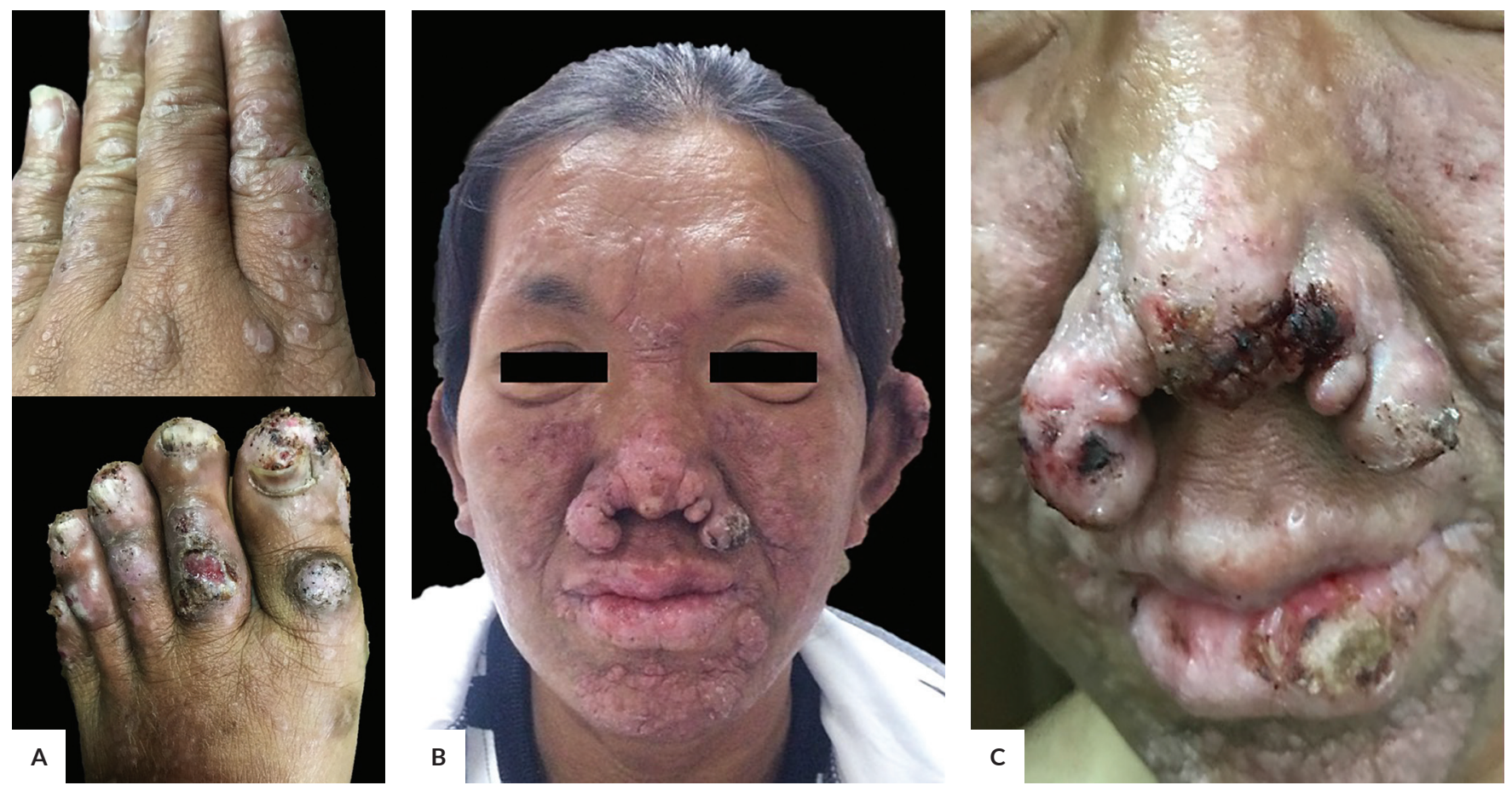

Figure 1. Cutaneous findings upon consultation. A. Multiple well-defined, round to irregularly-shaped, flesh-colored to erythematous, verrucous papules and plaques, some with noted crusting and ulceration, acral areas. B. Multiple welldefined erythematous to pale-pink plaques and nodules, central face and ears, with loss of bilateral lateral eyebrows. C. Close-up view of the nose showing well-defined nodular to polypoidal protrusions from the nasal tip and alae, with conspicuous alar rim and nasal tip deformities. 


\begin{tabular}{lclc}
\multicolumn{1}{c}{ Motor } & Nerve & Right & Left \\
Eye closure & Facial & Strong & Strong \\
$5^{\text {th }}$ finger out & Ulnar & Strong & Strong \\
Thumb up & Median & Strong & Strong \\
Wrist up & Radial & Strong & Strong \\
Foot up & Peroneal & Strong & Strong \\
\hline \multicolumn{1}{c}{ Sensory } & & Right & Left \\
Eyes & & Normal blink reflex \\
Palms & & 0 & 0 \\
Soles & & 0 & 0 \\
\hline
\end{tabular}

$\mathrm{O}=$ orange filament test

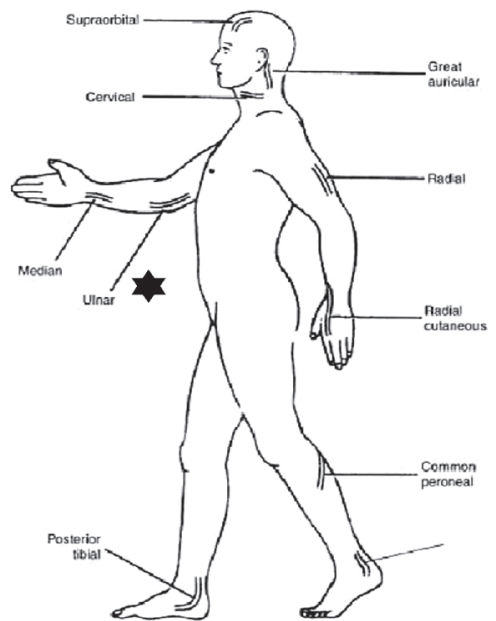

Figure 2. Nerve function assessment. There was enlargement and tenderness of the left ulnar nerve. On motor assessment, no muscle weakness was noted. On sensory assessment, there was note of loss of protective sensation represented by the patient only responding to orange filament on monofilament testing. Rest of the nerve function assessment was normal.
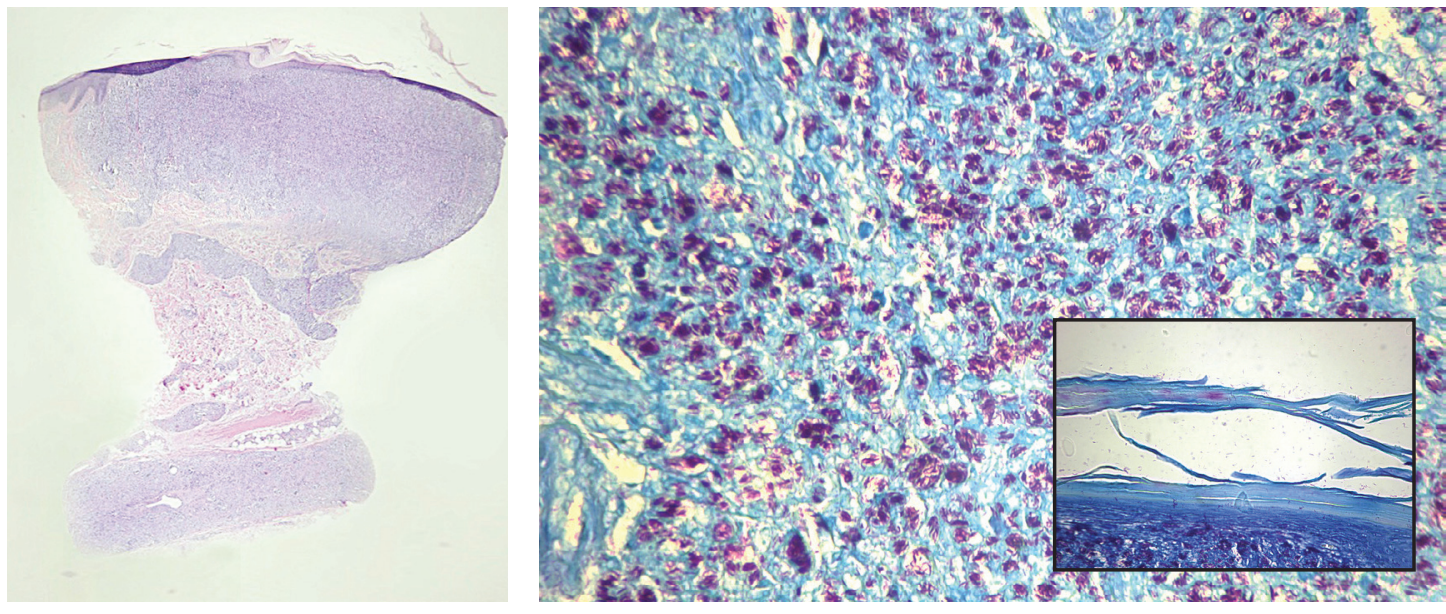

Figure 3. Histopathologic Findings. A. Hematoxylin-eosin (H\&E) stain of skin biopsy taken from a verrucous papule on the left dorsal hand, showing diffuse granulomatous dermatitis consistent with Hansen's disease, with diffuse lymphohistiocytic infiltrates in the superficial to deep dermis surrounding vessels and nerves, nodular infiltrates of foamy histiocytes, and multinucleated giant cells (scanning). B. Fite-Faraco stain showing numerous globi of acid-fast bacilli (40x). Inset. Conspicuous bacterial shedding from the stratum corneum (40x).

susceptible to all anti-retroviral medications on HIV drug resistance analysis. However, the patient expired prior to initiation of highly active retroviral therapy (HAART).

\section{DISCUSSION}

Peripheral nerve involvement is one of the diagnostic criteria of leprosy. However, the clinical presentation of verrucous papules and plaques is an uncommon presentation. As of 2014, there have only been 25 cases of verrucous leprosy. ${ }^{4-7}$ Nonetheless, along with the patient's clinical presentation, the positive Fite Faraco stain and slit skin smear of solid globi of acid-fast bacilli supported the diagnosis of lepromatous leprosy.

In HIV co-infection, it appears that the patient's CMI, and not the HIV infection per se, alters the clinicoimmunopathological spectrum of leprosy. To illustrate, in HIV-infected patients, the introduction of HAART has been shown to reveal latent leprosy infection. Most patients belong to the borderline tuberculoid spectrum. ${ }^{2,8}$ This represents the immune reconstitution disease (IRD), wherein the CMI recovers coinciding with the increase in the peripheral CD4 count leading to clinical manifestations of leprosy. 
CD4 T-lymphocytes, the principal target cells of HIV infection, have been shown to be normal in number from biopsy of leprosy lesions. The leprosy granuloma is less activated, with lower rate of apoptosis and cell turnover, and lower risk of HIV-infected cell recruitment compared to TB granuloma. ${ }^{9}$ This so-called 'granuloma paradox', however has only been studied among HIV patients with paucibacillary leprosy. The relatively preserved locus of lesional CD4 cells supports the clinical spectrum of leprosy not altered by HIV infection. In patients with lepromatous leprosy/HIV co-infection, however, similar findings cannot be deduced as studies in this subset of patients are lacking. ${ }^{10}$ The poor CMI response in lepromatous leprosy would approach the low peripheral CD4 count, thereby reflecting what appears to be of parallel course, albeit progressing independently.

It can be speculated that lepromatous leprosy in an HIV patient implies a very low peripheral CD4 count, suggesting severe immunosuppression. This type of co-infection is rarely seen probably owing to the long incubation period of leprosy, wherein patients at the time of HIV diagnosis, may have already succumbed to premature death from AIDS-related infections prior to manifesting lepromatous leprosy. ${ }^{11}$ Poor health-seeking behavior may also contribute to underdiagnosis of leprosy among patients with HIV. ${ }^{9}$ The co-existence of lepromatous leprosy as an opportunistic mycobacteriosis remains to be explored. ${ }^{8}$

From an equally important viewpoint, in patients with lepromatous leprosy, what would trigger investigation for an immunodeficiency state? In this case, it is the patient's atypical presentation. There have been reports of leprosy presenting with variant of histoid nodules in patients with untreated HIV of long duration. ${ }^{11}$ In 2014, a case report of verrucous leprosy with HIV infection was reported, in the borderline tuberculoid spectrum. ${ }^{4}$ The pathology behind verrucous leprosy is unclear to this date; however, previous reports have enumerated possible factors namely decreased sensation, chronic irritation and anhidrosis. ${ }^{5-7}$ HIV, being neuropathic, may work synergistically with leprosy in nerve damage contributing to verrucous development. ${ }^{4}$ Hence, leprosy presenting with atypical cutaneous manifestations may warrant search for HIV co-infection.

\section{CONCLUSION}

Rarely, lepromatous leprosy may be encountered in the setting of untreated, severe immunodeficiency. HIV testing in lepromatous leprosy should be considered in patients presenting with atypical cutaneous manifestations, such as verrucous leprosy. However, atypical or not, physicians must maintain a high index of suspicion, and HIV testing should be offered to all suspected cases.
The independent courses of HIV and leprosy and the preservation of the local T-cell mediated immune response may explain the responsiveness of patients with HIV/ leprosy co-infection to standard MDT. HIV is treated with HAART and leprosy is treated with MDT. Despite treatment of HIV and leprosy as separate conditions, the goal is to address the patient's depressed cell-mediated immune response, which appears to be the fulcrum of infection in both diseases.

\section{Statement of Authorship}

All authors approved the final version submitted.

\section{Author Disclosure}

All authors declared no conflicts of interest.

\section{Funding Source}

This paper was funded by the authors. No external funding agency.

\section{REFERENCES}

1. Ridley DS, Jopling WH. Classification of leprosy according to immunity. A five-group system. Int J Lepr Other Mycobact Dis. 34(3):255-73.

2. Lockwood DNJ, Lambert SM. Human immunodeficiency virus and leprosy: An update. Dermatol Clin. 2011;29(1):125-8.

3. Pires CAA, Neto FOMJ, de Albuquerque NC, Macedo GMM, Batista $\mathrm{K}$ de NM, Xavier MB. Leprosy reactions in patients coinfected with HIV: Clinical aspects and outcomes in two comparative cohorts in the Amazon Region, Brazil. PLoS Negl Trop Dis. 2015;9(6):1-14.

4. Manjare A, Tambe S, Phiske M, Jerajani H. Atypical presentation of leprosy in HIV. Indian J Lepr. 2010;82(2):85-9.

5. Medeiros MZ, Hans Filho G, Takita LC, Vicari CFS, Barbosa AB, Couto DV. Verrucous lepromatous leprosy: A rare form of presentation - Report on two cases. An Bras Dermatol. 2014;89(3):481-4.

6. Yuchua-Guillen A, Dofitas BL. Atypical Hansen's disease presenting as florid verrucous plaques on the lower extremities: A case report. Int J Dermatol. 2012;51(6):697-701.

7. Richard EB, Williamson EA, Jackson SM, Stryjewska BM. A rare form of Hansen's disease presenting as filiform verrucous papules on the feet. JAAD Case Reports. 2016;2(2):105-7.

8. Talhari C, Mira MT, Massone C, et al. Leprosy and HIV coinfection: a clinical, pathological, immunological, and therapeutic study of a cohort from a Brazilian referral center for infectious diseases. J Infect Dis. 2010;202(3):345-54.

9. Ustianowski AP, Lawn SD, Lockwood DN. Interactions between HIV infection and leprosy: a paradox. Lancet Infect Dis. 2006;6(6):350-60.

10. Sampaio EP, Caneshi JR, Nery JA, et al. Cellular immune response to Mycobacterium leprae infection in human immunodeficiency virusinfected individuals. Infect Immun. 1995;63(5):1848-54.

11. Massone C, Talhari C, Ribeiro-Rodrigues R, et al. Leprosy and HIV coinfection: a critical approach. Expert Rev Anti Infect Ther. 2011;9(6):701-10. 